\title{
Investigation of ionospheric TEC changes related to the 2008 Wenchuan earthquake based on statistic analysis and signal detection*
}

\author{
Jianyong $\mathrm{Li}^{1}$ Guojie Meng ${ }^{1, \star}$ Min Wang ${ }^{1}$ \\ Hua Liao $^{2}$ and Xuhui Shen ${ }^{1}$ \\ ${ }^{1}$ Institute of Earthquake Science, China Earthquake Administration, Beijing 100036, China \\ ${ }^{2}$ Earthquake Administration of Sichuan Province, Chengdu 610041, China
}

\begin{abstract}
Ionospheric TEC (total electron content) time series are derived from GPS measurements at 13 stations around the epicenter of the 2008 Wenchuan earthquake. Defining anomaly bounds for a sliding window by quartile and 2-standard deviation of TEC values, this paper analyzed the characteristics of ionospheric changes before and after the destructive event. The Neyman-Pearson signal detection method is employed to compute the probabilities of TEC abnormalities. Result shows that one week before the Wenchuan earthquake, ionospheric TEC over the epicenter and its vicinities displays obvious abnormal disturbances, most of which are positive anomalies. The largest TEC abnormal changes appeared on May 9, three days prior to the seismic event. Signal detection shows that the largest possibility of TEC abnormity on May 9 is $50.74 \%$, indicating that ionospheric abnormities three days before the main shock are likely related to the preparation process of the $M_{\mathrm{S}} 8.0$ Wenchuan earthquake.
\end{abstract}

Key words: GPS; total electron content (TEC); earthquake precursor; abnormal signals; hypothesis test CLC number: P352.4 Document code: A

\section{Introduction}

Ionospheric disturbance related to earthquakes was first found in 1960s (Barnes and Leonard, 1965). Researchers mostly analyze such ionosphere parameters, as critical frequency, peak electron density of $F_{2}$ layer, and total electronic content, in an effort to derive possible precursors before large earthquakes (Datchenko et al, 1972; Liu et al, 2000a, 2001b, 2004, 2006). Pulinets (1998) proposed that satellites could be employed to capture ionospheric anomalies for short-term and impendingearthquake prediction. Electro-magnetic disturbances related to earthquakes are not only confined to Earth lithosphere, but also appear within atmosphere, magnetosphere due to lithosphere-atmosphere-ionosphere coupling (Cai et al, 2007). Nowadays extensive studies of earthquake ionospheric precursors are being carried out in more than twenty countries. With more and more

\footnotetext{
* Received 6 July 2009; accepted in revised form 15 September 2009; published 10 October 2009.

•Corresponding author. e-mail: mgj@seis.ac.cn
}

GPS stations established worldwide, researchers are concentrating on monitoring ionospheric changes using GPS TEC (total electron content). Researches on the methods of ionospheric anomaly identification (Pulinets and Boyarchuk, 2004; Dautermann et al, 2007) and feasibility verification of seismic ionospheric precursors (Du et al, 1998) have been continually undergoing.

Previous statistical analyses on ionospheric changes prior to some earthquakes show that obvious abnormal TEC disturbances occur over epicenters and their vicinities several days before the occurrence of earthquakes. Ionospheric TECs decrease significantly, and anomaly crest moves toward the equator (Liu et al, 2000b, 2001a, 2009; Wu et al, 2005; Zhang et al, 2007).

A $M_{\mathrm{S}} 8.0$ earthquake happened in Wenchuan county, Sichuan province, China at 14:28:04.0 (Beijing time) on May 12, 2008, with a focal depth of $14 \mathrm{~km}$. After the main shock, 191 aftershocks occurred within one month, among which four aftershocks are larger than $M_{\mathrm{S}} 6.0$. Using partial GPS data from the Crustal Movement Observation Network of China (CMONOC) and IGS iono- 
spheric TECs, Lin et al (2009), Ma et al (2008), Zhao et al (2008b) and Zhu et al (2009) reported that the ionospheric abnormal disturbances occurred over the seismogenic zone during one week before and after the earthquake. Moreover, the abnormality pattern has a conjugate structure, showing a tendency of drifting to magnetic equator (Lin et al, 2009). Research on TEC derived from 58 GPS receivers around China and global ionosphere map (GIM) shows that the abnormal enhancement before the Wenchuan earthquake is most possibly a seismo-ionospheric signature (Zhao et al, 2008a).

However, because of the limited number of GPS stations used by previous researches, and stations far from the epicenter, more analyses on TEC changes are highly necessary. In this paper, we have derived TEC time series from much more GPS stations, including station LUZH, closest to the epicenter of main shock out of all the stations of CMONOC, and all the twelve stations of Sichuan continuous GPS network (SCGN), established and operated by Earthquake Administration of Sichuan Province. The characteristics of ionospheric TEC disturbances are further analyzed and the probabilities of TEC anomalies are quantitatively computed by using Neyman-Pearson signal detection method.

\section{GPS data and TEC computation}

Many factors can give rise to ionospheric disturbances, such as solar activity and magnetic disturbance. In order to derive ionospheric disturbances and study relationship between ionospheric disturbances and seismic activities, we refer to the following principles to analyze TEC changes. First of all, the impact of solar activity or magnetic storm should be ruled out. Secondly, selected stations should be within the scope of earthquake preparation area. Finally, stations need to have certain relativity in spatial distribution (Dautermann et al, 2007).

Dobrovolsky et al (1979) pointed out that various magnitudes of earthquakes have corresponding preparation area sizes and the relationship $\rho=10^{0.43 M}$ holds, where $\rho$ and $M$ denote radius of preparation area and magnitude, respectively. Then we can derive a radius of $2754 \mathrm{~km}$ for the Wenchuan earthquake. Six stations, LUZH, LHAS, DLHA, XIAG, XNIN, XIAA and KMIN, belonging to CMONOC, are located in the seismogenic zone. However, only the station LUZH are taken into consideration in the research, considering that LHAS,
DLHA, XIAG, XNIN, XIAA and KMIN are relatively far from the epicenter and no other station lies in between these stations and the epicenters to verify TEC variations. Moreover, GPS data recorded at the twelve stations of the SCGN network are used in this research (see Table 1 and Figure 1).

Table 1 The information of GPS stations selected

\begin{tabular}{ccc}
\hline Station code & $\begin{array}{c}\text { The distance from the epicenter } \\
\text { of the main shock } / \mathrm{km}\end{array}$ & $\begin{array}{c}\text { Observation } \\
\text { network }\end{array}$ \\
\hline PIXI & 35.8 & SCGN \\
QLAI & 72.6 & SCGN \\
YAAN & 119.2 & SCGN \\
MYAN & 135.5 & SCGN \\
ZHJI & 109.5 & SCGN \\
CHDU & 74.5 & SCGN \\
RENS & 111.2 & SCGN \\
JYAN & 119.2 & SCGN \\
LESH & 162.6 & SCGN \\
ROXI & 197.7 & SCGN \\
NEIJ & 225.4 & SCGN \\
YBIN & 270.5 & SCGN \\
LUZH & 305.8 & CMONOC \\
\hline
\end{tabular}

Note: SCGN and CMONOC represent Sichuan continuous GPS network, and the Crustal Movement Observation Network of China, respectively.

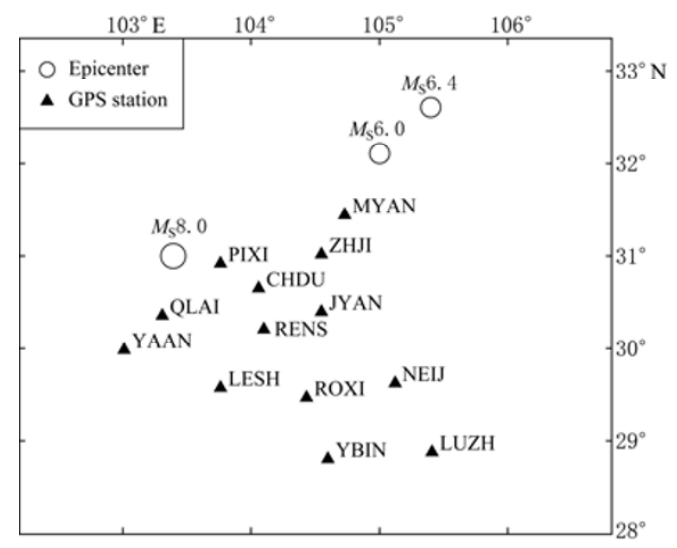

Figure 1 The epicenters of Wenchuan earthquake and its aftershocks and the distribution of continuous GPS stations.

Ionospheric TEC can be computed on the basis of refraction effect while electromagnetic wave propagates through ionosphere. A thin-shell model is usually employed to represent the Earth's ionosphere, under assumption that TEC are concentrated at a thin-shell at fixed height $(H)$ in a range of $350-400 \mathrm{~km}$. The oblique TEC, the integral of the electron density over a line of sight from a ground receiver to a satellite on the signal propagation path, can be calculated and then be converted to vertical TEC (VTEC), which is the projection of oblique TEC on the thin-shell, using an elevation mapping function (Dautermann et al, 2007). 
Here we set $H$ as $350 \mathrm{~km}$ and process GPS data from May 1 to June 30, 2008, of the above 13 stations, and then obtain TEC time series.

\section{Analysis of ionospheric TEC distur- bances}

Envelope method in statistics is mostly used to identify the significance of disturbances. The upper and lower bounds of TEC variations can be determined at different confidence levels.

Firstly, we compute the median of TEC values preceding and following ten days of each specified TEC and the associated inter-quartile range $R_{\mathrm{IQ}}$, to construct upper bound $\bar{x}+R_{\mathrm{IQ}}$ and lower bound $\bar{x}-R_{\mathrm{IQ}}$. The median for a sliding window, which is 20 days long, is assumed as background TEC. Under the assumption of normal distribution with mean $\mu$ and standard deviation of TECs, the expected value of $\bar{x}$ and $R_{\mathrm{IQ}}$ are $\mu$ and
$1.34 \sigma$, respectively (Liu et al, 2004). If an observed TEC falls out of either the associated lower or upper bounds, it is declared at confidence level of about $82 \%$ that a lower or upper abnormal signal is detected.

Figure 2 shows TEC time series of all the 13 stations. The abscissa represents time and vertical axis represents TEC values. It can be seen that TEC values of all the stations are significantly beyond the upper bound on May 3, 4, 9, 21 and 28, implying that positive anomaly disturbances appeared in these days. On May 7 and 8 , ionospheric TEC value are significantly lower than background TEC. TEC values of all the stations are beyond the lower bound, indicating occurrence of negative anomalies. Before the $M_{\mathrm{S}} 6.0$ aftershock on May 18, negative anomalies appeared at the stations CHDU, RENS, YBIN, ZHJI, MYAN and PIXI on May 17. TEC values before the $M_{\mathrm{S}} 6.4$ aftershock on May 25 are characteristic of positive disturbances.

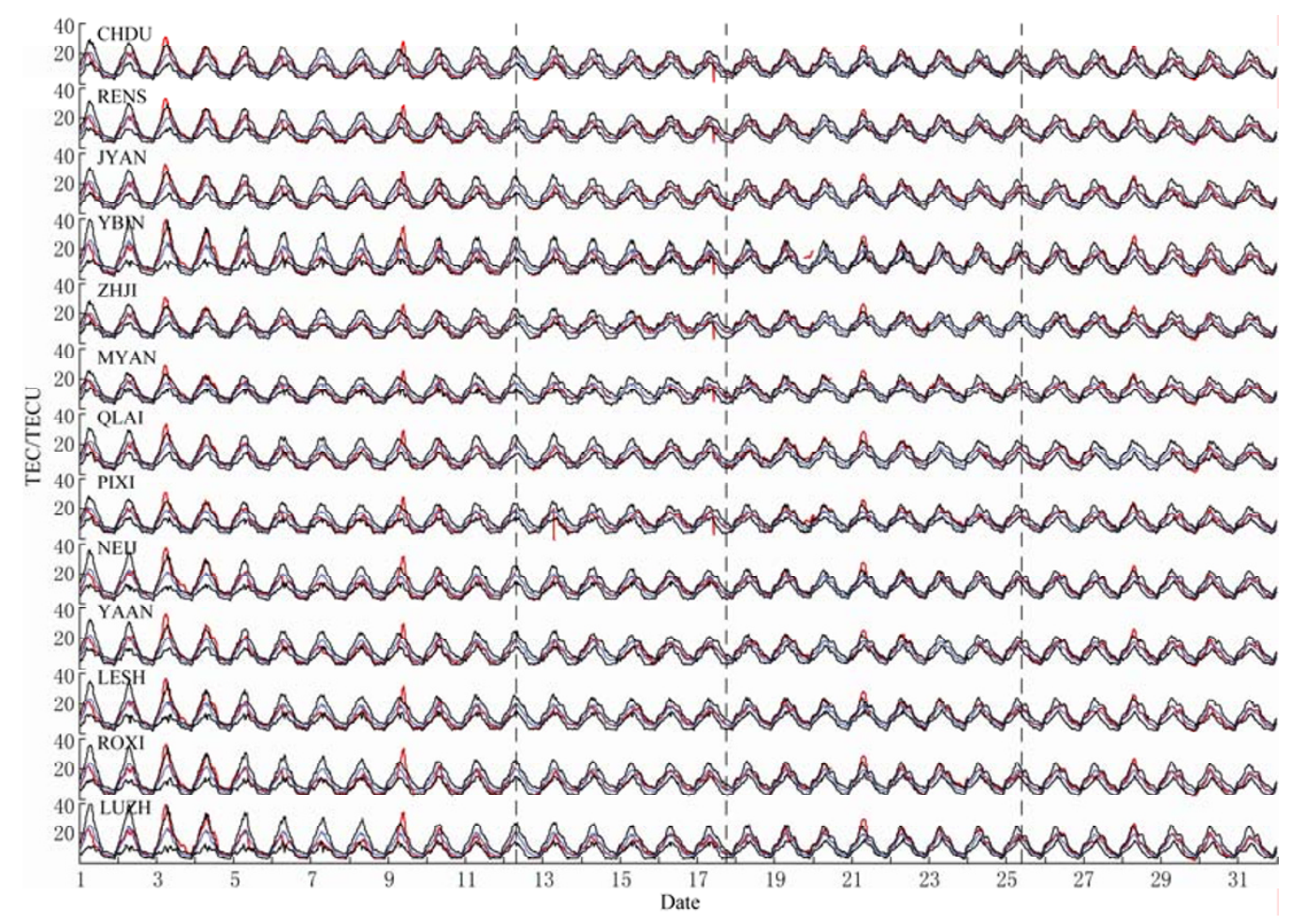

Figure 2 GPS TEC time series in May of 2008. The red curve shows TEC directly inferred from GPS phase data, and the blue curves represent background TEC. The black curves represent the upper band and the lower band. The vertical lines represent occurrence of the earthquakes.

In order to show ionospheric disturbance more clearly, we take difference to observed TEC and associated background values. Difference values are denoted by $D_{\mathrm{TEC}}$ here. When a TEC value is not beyond the up- per or the lower bounds, or data missing, its TEC difference value is fixed as zero. Figure 3 a shows the time series of $D_{\mathrm{TEC}}$, with quartiles as abnormal bounds.

TEC difference values which are greater than zero 
mean that they are beyond the upper bound. Those less than zero imply they are beyond the lower bound. If a TEC value is not beyond the upper and lower bound or data missing appears, TEC difference is fixed as zero. The vertical dashed lines represent the occurrence time of the main shock and subsequent two $M_{\mathrm{S}}>6.0$ aftershocks on May 18 and 25, respectively. It can be seen clearly that many TEC anomalous disturbances appeared before and after the main shock and the two aftershocks. The number of positive anomalies is much more than

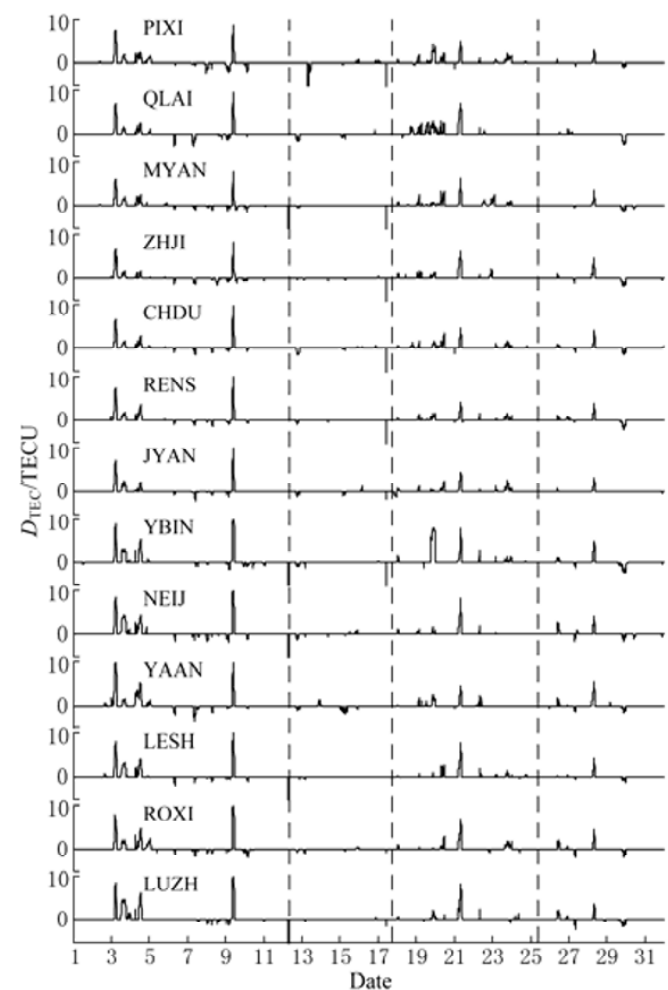

(a) that of negative anomalies. The positive abnormality values are much greater than the negative anomalies. TEC disturbances of several stations are larger than 10 TECU three days before the main shock. On May 17, negative TEC anomalies reach 5 TECU. TEC enhancements at some stations are greater than 5 TECU on May 21 , four days before the $M_{\mathrm{S}} 6.4$ aftershock on May 25 . Positive anomalies, greater than 3 TECU, appeared on May 28, three days after the $M_{\mathrm{S}} 6.4$ aftershock.

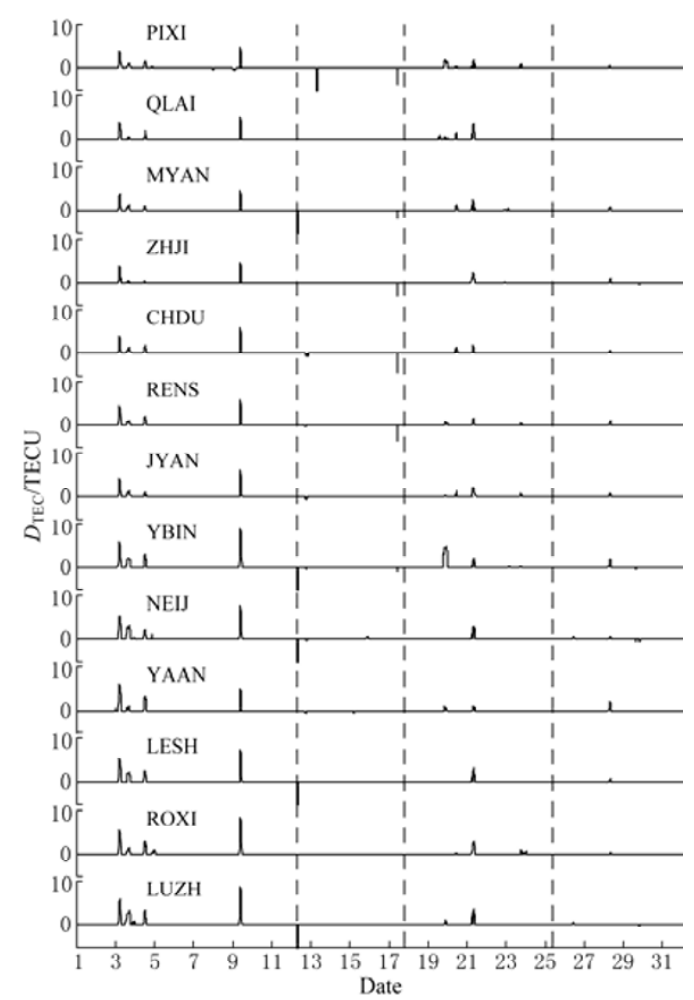

(b)

Figure 3 (a) TEC differences $\left(D_{\mathrm{TEC}}\right)$ in May of 2008 with quartiles as abnormal bounds; (b) TEC differences in the same period as (a), but with 2-standard deviation as abnormal bounds. The vertical dashed lines represent the occurrence time of the earthquakes.

In order to determine how significant the TEC disturbances are, we compute their standard deviations, and establish a new upper bound $\bar{x}+2 \sigma$, and a lower bound $\bar{x}-2 \sigma$. Here $\bar{x}$ is the median of TEC values of preceding and following ten days, $\sigma$ the standard deviation of a sliding window. Statistically, if a TEC value is beyond either the upper or lower bounds, we declare, at confidence level of $95 \%$, that a upper or lower abnormal signal is detected. We take the difference to TEC values and result is represented by $D_{\mathrm{TEC}}$. Meanwhile the associated upper or lower bounds are calculated. Figure $3 \mathrm{~b}$ shows resultant time series of TEC difference. It can be seen that the TEC values of all the stations are beyond upper bounds on May 3, 4, 9, 21 and 28, implying that positive anomaly disturbances occurred in these days, and the largest disturbances, more than 5 TECU, appeared on May 3 and May 9. Comparing Figure 3a with Figure $3 \mathrm{~b}$, we can see obviously that more abnormalities can be detected at a confidence level of $82 \%$. But by 2-standard deviation, smaller TEC disturbances are not any longer beyond upper and lower bound as a result of increased confidence level. Negative anomalies detected by quartile method are not significant any longer. But larger positive TEC disturbance are still beyond upper 
bounds. The disturbances on May 3 and May 9 are still significant at $95 \%$ confidence level.

Are these disturbances associated with the $M_{\mathrm{S}} 8.0$ Wenchuan earthquake? As mentioned above, other factors, such as solar activity, can also cause ionosphere TEC variation. Therefore, it is highly necessary to analyze such indices as indicator of solar activity and geomagnetic disturbance.

Figure 4 shows solar $D_{s t}$ index, solar flux $F_{10.7}$ and geomagnetic $K_{p}$ in the period of May 2008. It can be seen that solar $D_{s t}$ approximates $-30 \mathrm{nT}$ during May 1-6 and May 21-24. $F_{10.7}$ solar flux displays small changes, ranging from $67 \mathrm{sfu}$ to $73 \mathrm{sfu}$. $K_{p}$ values are greater than 4 during May 1-2 and May 5-6, suggesting that two weak geomagnetic storms occurred in this period. However, on May 9 geomagnetic environment was quiet, with $K_{p}$ less than 2. $K_{p}$ is greater than 3 during May 21-23 and May 28-30, implying that geomagnetic disturbance activities occurred in the two short periods. Solar and geomagnetic activities are relatively low five days before and after May 12, and ten days prior to the $M_{\mathrm{S}} 6.0$ aftershock on May 18, therefore it can be concluded that the ionospheric disturbances during the two periods did not contribute to space factors. However, a few days before and after May 25, ionosphere is very likely to be affected by solar and geomagnetic disturbance activities, as indicated by $K_{p} \geq 3$ and $D_{s t}$ near -30 $\mathrm{nT}$ during the two periods.
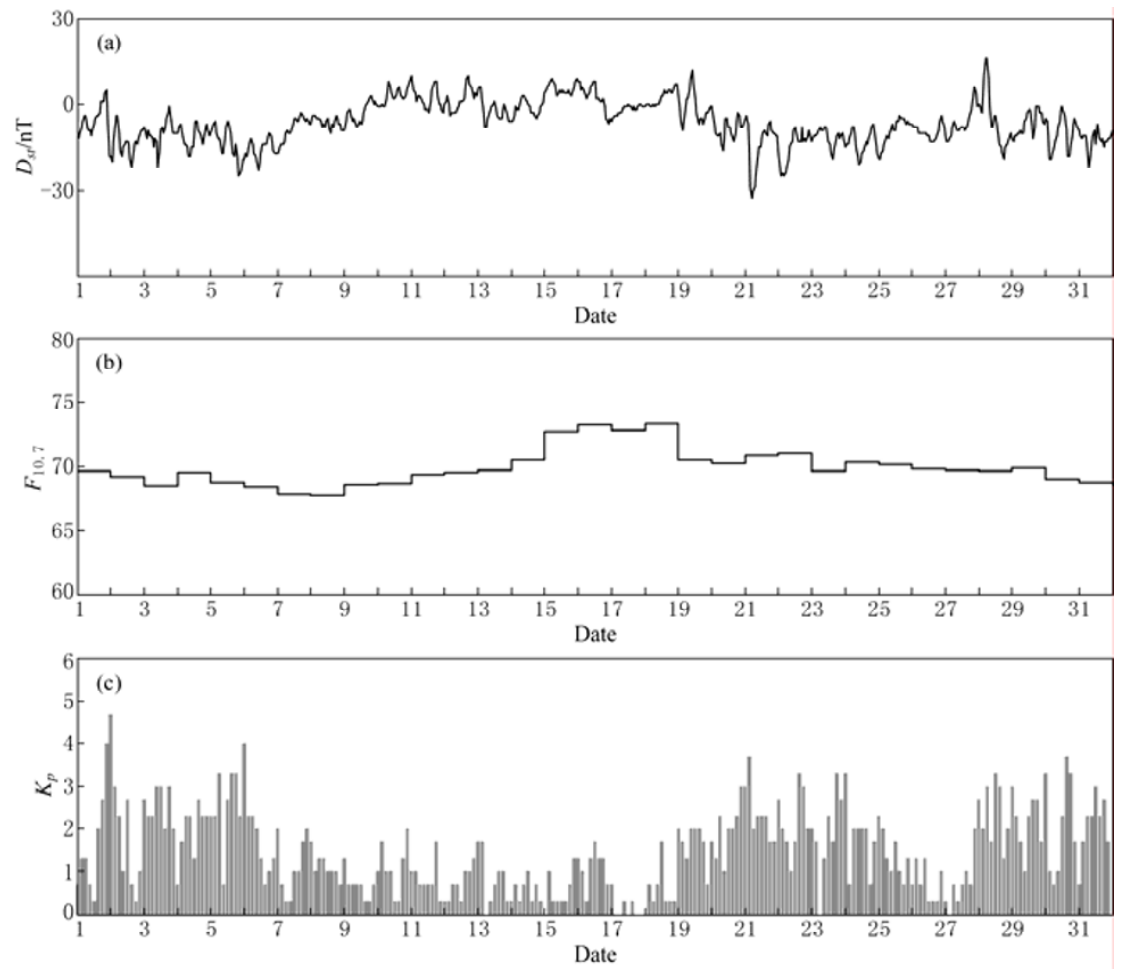

Figure 4 Time series of solar $D_{s t}$ index, solar $F_{10.7}$ flux and geomagnetic $K_{p}$ index in May of 2008 .

Taking the above three indices into consideration, TEC disturbances on May 3, 4, 21 and 28 can be attributed to solar activity and geomagnetic disturbance. However, the TEC reduction on May 7 and May 8, and the TEC enhancement on May 9 are possibly related to the preparation process of the $M_{\mathrm{S}} 8.0$ Wenchuan earthquake, when it is considered that all selected GPS stations here are close to the epicenter of the main shock.

Before the $M_{\mathrm{S}} 6.0$ aftershock of May 18 , negative anomalies occurred at the stations CHDU, RENS, YBIN, ZHJI, MYAN and PIXI on May 17, but they last very short period. TECs derived from other adjacent stations exhibit no anomalies. Therefore it can not be determined whether these negative anomalies are related to the Wenchuan earthquake or not.

\section{Probability of TEC anomaly}

\subsection{Principle of signal detection}

Various kinds of earthquake observation data are assumed to be in accord with Gaussian distribution (Zhang et al, 2001). Probability density for a time series 
without anomalies is supposed as $P_{0}(x)$, and hence as $H_{0}$ assumption, i.e., null hypothesis. Probability density distribution for a time series with anomalies is assumed as $P_{1}(x)$, and defined as $H_{1}$ assumption, i.e., alternative hypothesis. Identifying anomalies means to make a choice between a null and an alternative hypothesis $(\mathrm{He}$, 1990; Kay, 1998).

Figure 5 schematically shows the method to calculate the probability of an anomalous TEC time signal, where $T$ is detection threshold. If hypothesis $H_{0}$ is true, the false alert probability of hypothesis $H_{1}$ is $P_{0}$. The probability of hypothesis $H_{1}$ is represented by $P_{\mathrm{d}}$. A greater $P_{\mathrm{d}}$ value means a larger probability for detected abnormal signal. The more the value $B$ deviates from the $A$ value, the greater $P_{\mathrm{d}}$ will be, implying that the probability of detecting the value $B$ is greater. When detection threshold $T$ becomes less, the probability of detecting the value $B$ will be greater. If $H_{0}$ hypothesis is true, the false probability $P_{0}$ is large. $P_{0}, P_{\mathrm{d}}$ can be expressed respectively as follows:

$$
P_{0}=\int_{x}^{\infty} P_{0}(x) \mathrm{d} x,
$$

and

$$
P_{d}=\int_{x}^{\infty} P_{1}(x) \mathrm{d} x .
$$

If the probability of $H_{i}$, when $H_{j}$ is true, is assumed as $P\left(H_{i} ; H_{j}\right)$, then the reduction of the first type error probability is on the cost of increase of the second type error. In order to design a best signal detector, $P\left(H_{0} ; H_{1}\right)$ should be made smaller, or alternatively $1-P\left(H_{0} ; H_{1}\right)$, which equals to $P\left(H_{1} ; H_{1}\right)$, much bigger. The detection probability $P\left(H_{1} ; H_{1}\right)$ is a useful indicator in quantifying anomalies (Kay, 1998).

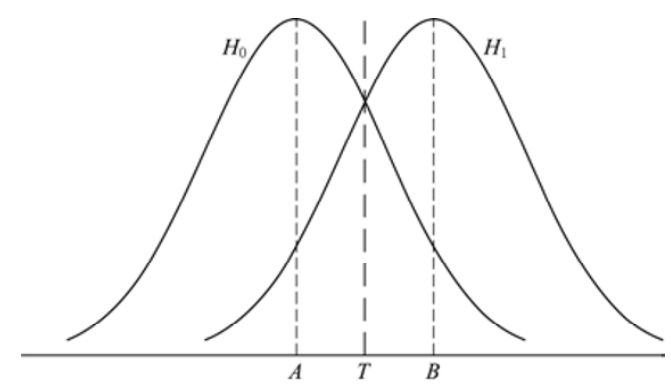

Figure 5 Schematic illustration of hypothesis test.

\subsection{Probabilities of TEC anomalies}

In order to further quantify the statistics associated with the detection of a signal, we apply the NeymanPearson (N-P) test of signal detection to TEC time series.
Firstly a stacking procedure is employed to average over 13 TEC time series, obtaining a "virtual TEC time series" (Figure 6). Then we subtract the time series from the TEC time series at each individual station to derive residual TEC time series, and define "signal" as the residual TEC for each day and "noise" as the residual TEC for all of the preceding and following ten days. Assuming a Gaussian distribution for both the noise and the signal, we compute their mean $\mu_{\mathrm{s}}$ and $\mu_{\mathrm{n}}$ over defined time interval. Their associated standard deviation $\sigma_{\mathrm{s}}$ and $\sigma_{\mathrm{n}}$ are also calculated meanwhile. The probability of false alarm $P_{\mathrm{fa}}$ is related to the detection threshold $T$ through (Kay, 1998; Dautermann et al, 2007):

$$
P_{\mathrm{fa}}=\frac{1}{\sqrt{2 \pi \sigma_{\mathrm{n}}^{2}}} \int_{T}^{\infty} \exp \left[-\frac{1}{2}\left(\frac{t-\mu_{\mathrm{n}}}{\sigma_{\mathrm{n}}}\right)^{2}\right] \mathrm{d} t .
$$

Using the complementary error function, the threshold $T$ can be calculated iteratively. The probability of detection $P_{\mathrm{d}}$ can be derived by

$$
P_{\mathrm{d}}=\frac{1}{\sqrt{2 \pi \sigma_{\mathrm{s}}^{2}}} \int_{T}^{\infty} \mathrm{e}\left[-\frac{1}{2}\left(\frac{t-\mu_{\mathrm{s}}}{\sigma_{\mathrm{s}}}\right)^{2}\right] \mathrm{d} t .
$$

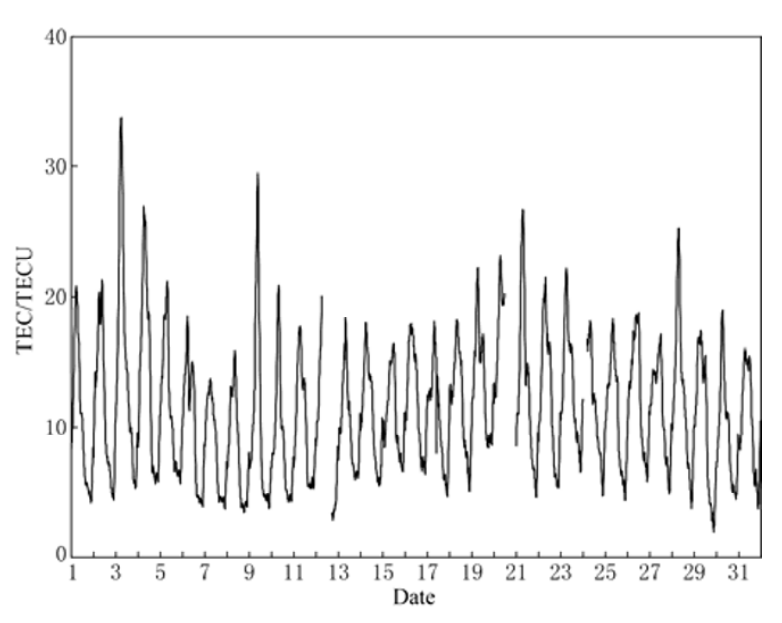

Figure 6 Stacked TEC time series in May of 2008.

We choose a probability of $P_{\mathrm{fa}}=0.01$, indicating the probability of false alert is $1 \%$. The probability of the abnormal TEC of all 13 stations in May 2008 can be derived from formula (4). Results are shown by Figure 7, in which the abscissa represents time, and vertical axis denotes $P_{\mathrm{d}}$ value, ranging from 0 to 1 . The $P_{\mathrm{d}}$ value of detection probability is like an indicator: the greater a $P_{\mathrm{d}}$ value is, the higher the possibility of an abnormal TEC is. Because data recording of the overall 13 stations were frequently interrupted after the main shock, due to 
power failure or instrumental errors, derived TEC values of these days are not continuous. Since N-P test requires that time series must be continuous, we can only calculate $P_{\mathrm{d}}$ values prior to the main shock.

As can be seen in Figure 7, on May 9, except JYAN station, $P_{\mathrm{d}}$ values of other 12 stations range from 0 to 0.5074 , indicating that the probability of abnormal TEC are up to $50.74 \%$ at largest. The $P_{\mathrm{d}}$ values on May 8 are also relatively high, which possibly results from TEC reduction on May 7 and May 8, and elevated TEC on May 9, since partial TEC data of May 7 and May 9 are involved in deriving the $P_{\mathrm{d}}$ values of May 8 . The $P_{\mathrm{d}}$ values of QLAI, YBIN, ROXI on May 11 may be caused by the interruption of TEC data on May 12. Although TEC values on May 3 and May 4 exhibit similar enhancements to May 9, $P_{\mathrm{d}}$ values during these two days are close to zero. To address what cause this difference, we further compute the signal and noises of all the 13 stations, as shown in Figure 8.

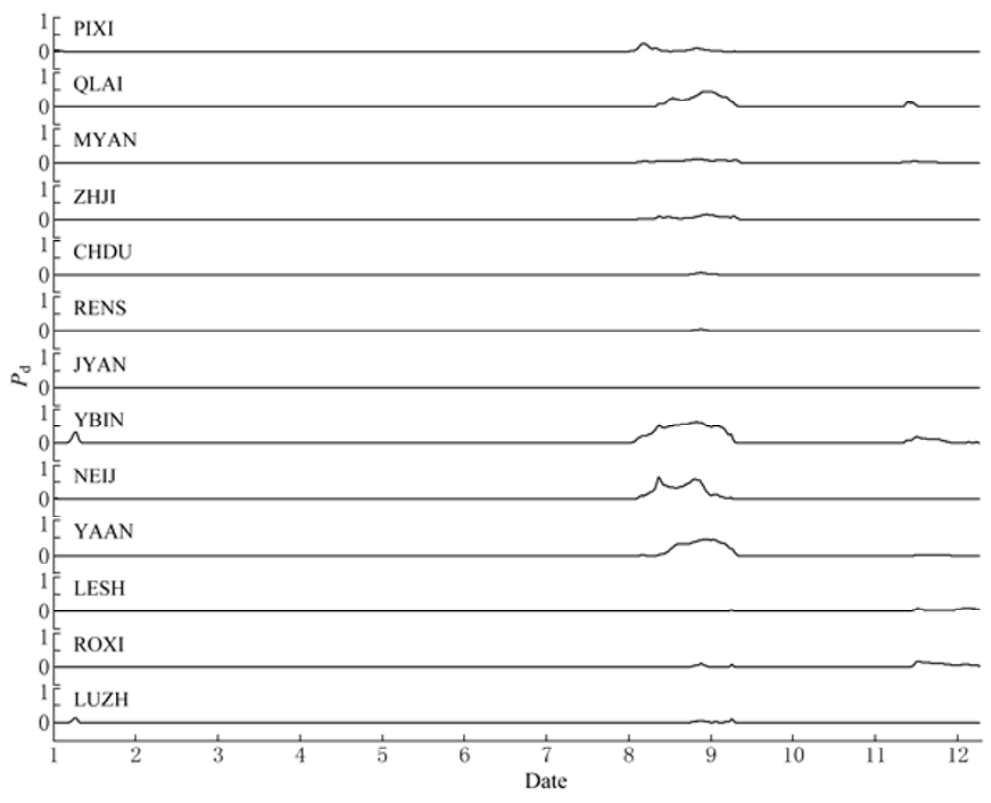

Figure $7 \quad P_{\mathrm{d}}$ values of GPS stations.

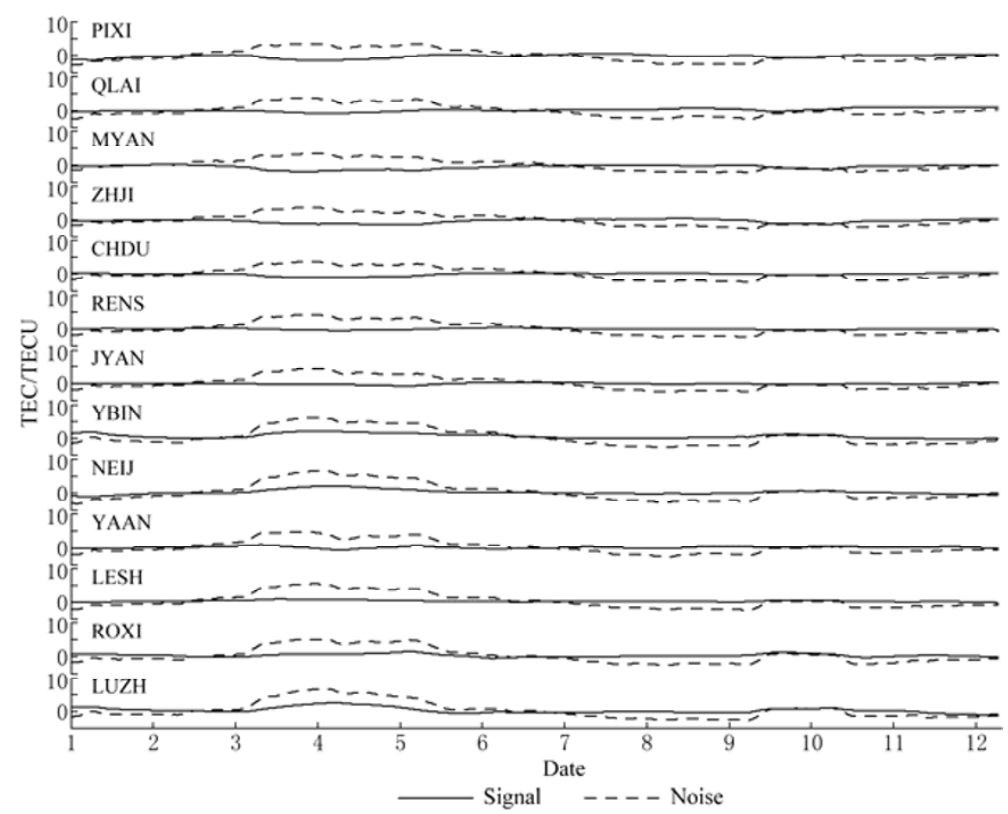

Figure 8 Signal and noise of TEC series in twelve days before the Wenchuan earthquake. 
The abscissa here represents time, and vertical axis denotes mean values of signal and noise. It can be seen that, though the mean values of signal on May 9 are a little larger than noise, the mean values of noise are significantly higher than signal on May 3, 4 and 5. Therefore lower $P_{\mathrm{d}}$ values on May 3 could be attributed to signal contamination by large noise, due to solar activity and a weak geomagnetic storm occurring in this period.

\section{Conclusions}

TEC time series are derived from GPS phase data of 13 continuous stations. We have identified ionospheric disturbances by statistical analysis, constructing lower and upper bounds with quartile and 2-standard deviation, respectively. Results show that some ionospheric TEC disturbances appeared a few days before the main shock and two aftershocks of the Wenchuan earthquake. The number of positive abnormal disturbances is larger than negative ones. TECs exhibit anomalous enhancement on May 3, 4, 9 and 21. Neyman-Pearson test demonstrates that the probabilities of TEC abnormalities on May 8 and May 9 are relatively higher than those of other days, with the largest up to $50.74 \%$. Referred to space factors, the unusually elevated TECs on May 3 and May 4 are possibly caused by solar and geomagnetic disturbance activity. Nevertheless, TEC enhancement on May 9 may be a precursor of the Wenchuan earthquake. After main shock, negative anomalies appeared at the stations CHDU, RENS, YBIN, ZHJI, MYAN and PIXI on May 17, but positive disturbances occurred on May 21, four days before the $M_{\mathrm{S}} 6.4$ aftershock of May 25. Taking space solar factors into account, we assume that the positive anomalies on May 21 are possibly caused by geomagnetic disturbance. However, before the $M_{\mathrm{S}} 6.0$ aftershock of May 18, TEC anomalies last very short period. It is difficult to determine whether these anomalies are related to the aftershock.

GIM (global ionosphere map) shows that abnormal TEC enhancement appeared on May 3 and May 9 around the Wenchuan area before the $M_{\mathrm{S}} 8.0$ earthquake. TEC anomalies on May 3 are supposed to be caused by a geomagnetic storm (Zhao et al, 2008a). Here we have analyzed the TECs derived from GPS data of Sichuan GPS network and the station LUZH of CMONOC, which are close to epicenter of main shock and aftershocks of the 2008 Wenchuan earthquake. The GPS observations of these stations are not analyzed by previous researches. In this sense, this research improves the pattern of ionospheric changes related to the strong earthquake. We have identified TEC enhancements on May 3 and May 9, reconfirming the previous researches. At the same time, we quantitatively estimate the probabilities of abnormal TECs, which are more objective in defining ionospheric variation. We find that the probabilities of TEC enhancement on May 3 are not significant. However, the TEC anomalies on May 9 are of higher probability.

Three statistical methods are applied here to analyze ionospheric TEC time series of 13 selected stations. It is quite clear that TEC anomalies display different characteristics, both in number and in amplitude at various confidence levels. Therefore it is crucial to find objective criteria in deriving ionospheric TEC abnormalities. Since GPS measurement is characterized by high precision, quasi-real time and high resolution in monitoring ionospheric TEC variations, it has great potential in probing into relationship between ionosphere abnormity and earthquake.

Acknowledgments This research is financially supported by the Key Technology Research and Development Program of China (2008BAC35B02). The authors acknowledge Earthquake Administration of Sichuan Province for providing partial GPS data in this research. We are indebted to Mrs. Tie Gu for her assistance in preliminary data processing.

\section{References}

Barnes R A and Leonard R S (1965). Observations of ionospheric disturbances following the Alaska earthquake. J Geophys Res 70: 1 250-1 253.

Cai J T, Zhao G Z, Zhan Y, Tang J and Chen X B (2007). The study on ionospheric disturbances during earthquakes. Progress in Geophysics 22(3): 695-701 (in Chinese with English abstract).

Datchenko E A, Ulomov V I and Chernyshova C P (1972). Electron density anomalies as the possible precursor of Tashkent earthquake. Dokl Uzbek Acad Sci 12: 30-32.

Dautermann T, Calais E, Haase J and Garrison J (2007). Investigation of ionospheric electron content variations before earthquakes in southern California, 2003-2004. J Geophys Res 12: 1 230-1 231.

Dobrovolsky I P, Zubkov S I and Miachkin V I (1979). Estimation of the size of earthquake preparation zones. Pure Appl Geophys 117: 1 025-1 044

Du P R, Jiang H R and Guo Q S (1998). Research on possibility of ionospheric anomalies as an earthquake precursor. Earthquake 18(2): 119-126 (in Chinese with English abstract).

He S H (1990). Detection theory of precursory anomaly and decision-making threshold in earthquake prediction. Earthquake (1): 30-36 (in Chinese with English abstract).

Kay S M (1998). Fundamentals of Statistical Signal Processing, Volume II: Estimation Theory. Prentice Hall Professional Technical Reference, Upper Saddle River, New Jersey, 20-92.

Lin J, Wu Y, Zhu F Y, Qiao X J and Zhou Y Y (2009). Wenchuan earthquake ionosphere TEC anomaly detected by GPS. Chinese J Geophys 52(1): 297-300 (in Chinese with English abstract).

Liu J Y, Chen Y I, Chen C H, Liu C Y, Chen C Y, Nishihashi M, Li J Z, Xia Y Q, 
Oyama K I and Hattori K (2009). Seismoionospheric GPS total electron content anomalies observed before the 12 May $2008 M_{\mathrm{W}} 7.9$ Wenchuan earthquake. J Geophys Res 114: A04320, doi:10.1029/2008JA013698.

Liu J Y, Chen Y I, Chuo Y J and Chen C S (2006). A statistical investigation of preearthquake ionospheric anomaly. $J$ Geophys Res 111: A05304, doi:10.1029/2005JA011333.

Liu J Y, Chen Y I, Chuo Y J and Tsai H F (2001a). Variations of ionospheric total electron content during the Chi-Chi earthquake. Geophys Res Lett 28(7): $1383-1386$.

Liu J Y, Chen Y I, Pulinets S A and Chuo Y J (2000a). Seismo-ionospheric signatures prior to $M>6.0$ Taiwan earthquakes. Geophys Res Lett 27(19): $3113-3116$.

Liu J Y, Chen Y I, Pulinets S A, Tsai Y B and Chuo Y J (2000b). Seismo-ionospheric signatures prior to $M \geq 6.0$ Taiwan earthquakes. Geophys Res Lett 27(19): 3 113-3 116.

Liu J Y, Chuo Y J and Chen Y I (2001b). Ionospheric GPS TEC perturbations prior to the 20 September 1999, Chi-Chi earthquake. Geophys Res Lett 28: $1383-1386$.

Liu J Y, Chuo Y J, Shan S J, Tsai Y B, Chen Y I, Pulinets S A and Yu S B (2004). Pre-earthquake ionospheric anomalies registered by continuous GPS TEC measurements. Annales Geophysicae 22: 1 585-1 593.

Ma X X, Jin H L and Meng G J (2008). Research on ionospheric anomalies before earthquakes detected by ground GPS observation data. Earthquake 28(4): 80-90 (in Chinese with English abstract).
Pulinets S A (1998). Strong earthquakes prediction possibility with the help of topside sounding from satellites. Advances in Space Research 21(3): $455-458$.

Pulinets S A and Boyarchuk K A (2004). Ionospheric Precursors of Earthquakes. Springer, Berlin, 71-88.

Wu Y, Qiao X J and Zhou Y Y (2005). Preseismic ionospheric TEC anomaly detected by ground-based GPS. Journal of Geodesy and Geodynamics 25(2): 36-40 (in Chinese with English abstract).

Zhang G M, Fu Z X and Gui X T (2001). Introduction to Earthquake Prediction. Science Press, Beijing, 125-127 (in Chinese).

Zhang Q, Wu Y, Lin J, Zhou Y Y, Yang S M and Li D Q (2007). On ionospheric TEC anomaly before earthquake. Journal of Geodesy and Geodynamics 27(3): 91-96 (in Chinese with English abstract).

Zhao B, Wang M, Yu T, Wan W, Lei J, Liu L and Ning B (2008a). Is an unusual large enhancement of ionospheric electron density linked with the 2008 great Wenchuan earthquake? J Geophys Res 113: A11304, doi: 10.1029/2008JA013613.

Zhao B Q, Wan W X, Wang M, Liu L B and Ning B Q (2008b). Recent advances on the ionospheric precursors of earthquakes and ionospheric variations prior to Wenchuan earthquake. Review of Science and Technology 26(11): 30-33 (in Chinese with English abstract).

Zhu F Y, Wu Y, Lin J, Zhou Y Y, Xiong J and Yang J (2009). Anomalous response of ionospheric VTEC before the Wenchuan earthquake. Acta Seismologica Sinica 22(2): 180-187 (in Chinese with English abstract). 